\title{
Molecular phylogeny of Indonesian Lymantria Tussock Moths (Lepidoptera: Erebidae) based on CO I gene sequences
}

\author{
Hari Sutrisno* \\ Laboratory of Entomology, Division of Zoology, Research Center for Biology, The Indonesian Institute of Sciences, \\ Jl. Raya Bogor Km 46 Cibinong 16911 \\ *Correspondent: sutrisnohari@yahoo.com
}

\begin{abstract}
Many species of Lymantria are important forestry pests, including L. dispar which is well known distributed from Asia to North America as an invasive species. Like of most other genera of moths, the systematic of this genus is still in dispute, especially on the monophyly and the relationship within this genus due to the fact that genus is very large and varied. This genus was morphologically defined only by a single aphomorphy. To clarify the monophyly of the genus Lymantria, to reveal the phylogenetic relationship among the Indonesian species, and to establish the genetic characters of Indonesian Lymantria, we analyzed 9 species of Indonesian Lymantria involving 33 other species distributed around the world based on nucleotide sequence variation across a 516-bp region in the CO I gene. The results showed that the base composition of this region was a high $\mathrm{A}+\mathrm{T}$ biased $(C: 0.3333)$. The results also showed that the monophyly of Lymantria was not supported by bootstrap tests at any tree building methods. Indonesian species was distributed into four different groups but the relationship among them was still in dispute. It indicates that relationships among the basal nodes (groups) proposed here were least valid due to the fact that the number of species may not be enough to represent the real number of species in the nature. Moreover CO I gene sequences alone were not able to resolve their relationships at the basal nodes. More investigations were needed by including more species and other genes that the more conserved.
\end{abstract}

Keywords: COI gene, Erebidae, Lepidoptera, Lymantria, phylogeny

\section{INTRODUCTION}

Many species of Lymantria are important forestry pests, including L. dispar. L. dispar asiatica (The Asian Gypsy Moth) is a serious tree pest in its native Asian range. This species feeds on over 500 species of trees and shrubs, including many conifers and hardwoods, although Quercus is the preferred host. The defoliation and weakening of hosts caused by Asian Gypsy Moth feeding increase their susceptibility to other pests and diseases and/or directly kill the host plant in some cases (Matsuki et al., 2001).

So far, there is no record of Lymantria which attack crops or cultivated plants in Indonesia except $L$. beatrix, that has been reported as one of the species that attacks seriously the cultivated mango in the center of mango production (Probolinggo, East Java) during March-May 2011 (Sutrisno et al., 2013). However, global trade forces us to watch any potential invasive species such as $L$. dispar which enters to Indonesia since several countries (China, Korea, Japan and North America) have been invaded by this species. Australian Quarantine has concluded that Asian Gypsy Moths have high risk based on risk analysis on several factors such as entry potential, establishment potential, spread potential following entry, economic impact, and environmental impact (Matsuki et al., 2001). Thus, accumulating any biological data such as the genetic characteristic of each native species, and the genetic relationship among them is necessary to distinguish them from any invasive species that are potential to enter Indonesia. Moreover, those data are needed to predict and evaluate their potential to become serious pests in the future. Due to ecosystem change, for examples trough monoculture practices, uncontrolled pesticides use, increasing temperature level and other habitat changes, native species might often become serious pests. For example, Arctornis riguata (Erebidae) that has been recorded in Tengger Mountain since 1948 as a native species with Annacardiacea as its host plant (Collenette, 1948), in 2011 their population was outbreak and defoliated about $1.2 \%$ of cultivated mango in Probolinggo, East Java (Sutrisno et al., 2013). 
Like of most other genera of moths, the systematic of this genus is still in dispute, especially on the monophyly and the relationship within this genus due to th largeness of this genus (about 167 species in the world) and the variation (Schintlmeister, 2004). This genus was only defined by a single aphomorphic character i.e. the extensile nature of the female ovipositor that, with the eighth segment structures, is as long as or longer than the ductus and bursa combined. The extended zone is mainly within the membrane between the ovipositor lobes and the eighth segments (Holloway, 1999). Moreover comprehensive studies on the systematic of this genus were very limited except the study on taxonomy that has been conducted by Schintlmeister (2004) and the study on the phylogeny base on molecular data by deWaard et al. (2010). The latter studied the phylogeny of this genus by involving about 36 species around the world but unfortunately not much Indonesian species were involved in their study even though there are about 24 species distributed in Indonesia. Therefore, a phylogenetic analysis of this genus involving all the available data is necessary to be conducted in order to clarify the phylogeny of this genus previously proposed.

There is no doubt that morphological character is very important to establish the genus but it is not always easy when we deal with a large and varied genus such as Lymantria. A lot of internal characters are probably useful, especially the genital characters, not only to confirm the monophyly of the genus but also to reconstruct the relationships among them. However, it is often difficult to score these characters due to the complexity of their structures and also the availability of the male and female genitalia itself. The adult of certain group are often difficult to be collected by using a light trap because they are not attracted to light sources. In fact, the male genitalia characters are very specific for each species in Lepidoptera. The other problem in employing the morphological characters is the objectivity of the observers; different observers will give different results when they work on the same sample specimens.

Molecular approach is one of the alternatives that can be applied to fill that gap. The huge number of characters resulted from a certain gene sequence is very powerful not only to differentiate among species within a large and varied genus but also to resolve the phylogenetic relationships among them, from lower to higher level. Among them, COI is more conserved and it is very suitable to identify a species since its sequence has a low variability (in general less than 1-2\%), even for the closely-related species its value is less than $1 \%$. Moreover, CO I gene is one of the most common to be considered in inferring the relationships among closely-related species in several groups of Lepidoptera, as individual gene or its combination with other genes (Sutrisno et al., 2006; Yamamoto \& Sota, 2007; Tsao \& Yeh, 2008; Kim et al., 2010).

In order to clarify the monophyly of the genus and the relationships of Indonesian Lymantria within this genus, we used mitochondrial CO I gene sequence to reconstruct the relationships among 9 species of Lymantria which are distributed in Indonesia involving other 33 species from the previous study (Armstrong and Ball, 2005; Ball and Armstrong, 2006; deWaard et al., 2010). In order to eliminate the bias, some species that were involved in the previous study were omitted from the analysis due to the fact that their sequence is too short $(<320-b p)$; they were L. singapura, L. simperi, L. todara and, L. subrosea (Table 2 ). The results of the study also will give benefit to the efforts in establishing the genetic characters of Indonesian Lymamtria. By establishing the data of the genetic identity of these pests in Indonesia, we can predict and justify any invasive species that enter Indonesia, especially those species that are morphologically difficult to be identified such as Lymantria group. Thus, by comparing their sequences, we can help the quarantine staff at the entry points to justify the status of pest species correctly.

\section{Materials ANd Methods}

\section{Moth specimens}

A total of 9 species of Lymantria were collected from different localities in Indonesia. Adult moths were col-

Table 1. Indonesian species selected for molecular study.

\begin{tabular}{|c|c|c|c|c|c|}
\hline No & Species & $\begin{array}{l}\text { No. acc } \\
\text { Genbank }\end{array}$ & $\begin{array}{l}\text { Voucher } \\
\text { specimen }\end{array}$ & Date \& Locality & Collector \\
\hline 1 & L. singapura & AB851467 & MZB101 & 6.x.2009. Halimun NP, West Java & Woro, Yayuk, Cholik, Sarino \\
\hline 2 & L. lepcha & AB851468 & MZB102 & 1.vi.2010. Halimun NP, West Java & Sutrisno, Darmawan, Sarino \\
\hline 3 & L. alexandrae & AB851469 & MZB104 & 2.ii.2010. Weda Bay, Halmahera & Suwito \& Cholik \\
\hline 4 & L. inordinata & $\mathrm{AB} 851470$ & MZB107 & 7.vi.2010. Halimun NP, West Java & Sutrisno, Darmawan, Sarino \\
\hline 5 & L. beatrix & AB851471 & MZB108 & 1.xi.2008. Halimun NP, West Java & Darmawan \\
\hline 6 & L. praetermissa & AB851472 & MZB109 & 17.iv.2009. Gunung Slamet, Central Java & Sutrisno \& Sarino \\
\hline 7 & L. temburong & AB851473 & MZB110 & 25.vi.2008. Halimun NP, West Java & Sutrisno \& Darmawan \\
\hline 8 & L. capnodes & AB851474 & MZB113 & 1.vi.2010. Halimun NP, West Java & Sutrisno, Darmawan, Sarino \\
\hline 9 & L. brunneiplaga & $\mathrm{AB} 851475$ & MZB114 & 3.iv.2012. Pesawaran, Lampung, Sumatra & Sutrisno, Cholik \& Darmawan \\
\hline
\end{tabular}


lected by using light traps and were preserved in absolute alcohol (96\%). All the species used in this study were presented in Table 1.

\section{Species identification}

Species identification was conducted based on external and internal characters. The genitalia slide was prepared by the custom method of boiling in $10 \%$ potassium hydroxide for about 10-11 minutes. Dissection of genitalia was performed under a binocular stereoscopic microscope.

\section{DNA extraction and sequencing CO I gene}

A non-destructive method which is modification from QIAGEN animal tissue protocol kit using spin column was used for DNA extraction from each moth individual (Sutrisno, 2012a). Firstly, the abdomen was removed from the body then was placed into a sterile 1.5 microtube and added $0.1 \mathrm{~mL}$ proteinase $\mathrm{K}(\mathrm{PK}) 1 \%$ buffer $(1 \% \mathrm{PK}$ buffer $=20 \mu \mathrm{L}$ proteinase $\mathrm{K}$ solution $(20 \mathrm{mg} / \mathrm{mL})$ in $180 \mu \mathrm{L}$ buffer ATL (QIAGEN). This abdomen then was incubated at $55^{\circ} \mathrm{C}$ for $2-4$ hours and was added a further $0.1 \mathrm{~mL}$ PK buffer and was incubated at $55^{\circ} \mathrm{C}$ for overnight. The next morning the abdomen was removed for morphological work. The tube containing the insect mixture was then treated by following the manual of QIAGEN animal tissue protocol kit using spin column.

The complete sequence primers used were LepF1: 5' ATT CAA CCA ATC ATA AAG ATA TTG G 3', and LepR1: 5' TAA ACT TCT GGA TGT CCA AAA AATCA $3^{\prime}$ The amplification was conducted in the following PCR conditions: one cycle of denaturation at $94^{\circ} \mathrm{C}$ for $10 \mathrm{~min}$, followed by 35 cycles, with each cycle consisting of denaturation at $92^{\circ} \mathrm{C}$ for $30 \mathrm{sec}$, annealing at $47^{\circ} \mathrm{C}$ for $30 \mathrm{sec}$, and extension at $72^{\circ} \mathrm{C}$ for $1 \mathrm{~min}$. $30 \mathrm{sec}$. These cycles were completed by final extension at $72^{\circ} \mathrm{C}$ for 10 min (Sutrisno, 2008; 2011; 2012a; 2012b; Hebert et al.,

Table 2. Species included in the analysis from the previous study.

\begin{tabular}{|c|c|c|c|c|}
\hline No & Species & Accession No & References & Note \\
\hline 1 & L. albescens & HM775517.1 & deWaard et al., 2010 & \\
\hline 2 & L. antennata & HM775530.1 & deWaard et al., 2010 & \\
\hline 3 & L. brunneiplaga & НM775536.1 & deWaard et al., 2010 & \\
\hline 4 & L. concolor & HM775537.1 & deWaard et al., 2010 & \\
\hline 5 & L. dispar & HM775753.1 & deWaard et al., 2010 & \\
\hline 6 & L. dissoluta & HМ775754.1 & deWaard et al., 2010 & \\
\hline 7 & L. ekeikei & HM775757.1 & deWaard et al., 2010 & \\
\hline 8 & L. flavida & HM775759.1 & deWaard et al., 2010 & \\
\hline 9 & L. fumida & HМ775764.1 & deWaard et al., 2010 & \\
\hline 10 & L. grisea & HМ775765.1 & deWaard et al., 2010 & \\
\hline 11 & L. lucescen & HM775766.1 & deWaard et al., 2010 & \\
\hline 12 & L. mathura & HM775772.1 & deWaard et al., 2010 & \\
\hline 13 & L. minomonis & HМ775790.1 & deWaard et al., 2010 & \\
\hline 14 & L. monacha & HM775793.1 & deWaard et al., 2010 & \\
\hline 15 & L. nassigi & HM775819.1 & deWaard et al., 2010 & \\
\hline 16 & L. narindra & HМ775820.1 & deWaard et al., 2010 & \\
\hline 17 & L. nebulosa & HM775821.1 & deWaard et al., 2010 & \\
\hline 18 & L. nephographa & HM775822.1 & deWaard et al., 2010 & \\
\hline 19 & L. obfuscata & HM775826.1 & deWaard et al., 2010 & \\
\hline 20 & L. panthera & HM775827.1 & deWaard et al., 2010 & \\
\hline 21 & L. plumbolis & HM775828.1 & deWaard et al., 2010 & \\
\hline 22 & L. pulvurea & HM775837.1 & deWaard et al., 2010 & \\
\hline 23 & L. rhapdota & HM775839.1 & deWaard et al., 2010 & \\
\hline 24 & L. schaeferi & HM775840.1 & deWaard et al., 2010 & \\
\hline 25 & L. semperi & HM775841.1 & deWaard et al., 2010 & Excluded (276-bp) \\
\hline 26 & L. sinica & HM775844.1 & deWaard et al., 2010 & \\
\hline 27 & L. singapura & HМ775842.1 & deWaard et al., 2010 & Excluded (266-bp) \\
\hline 28 & L. subrosea & HМ775849.1 & deWaard et al., 2010 & Excluded (313-bp) \\
\hline 29 & L. n. mathura & HM775847.1 & deWaard et al., 2010 & \\
\hline 30 & L. todara & HM775850.1 & deWaard et al., 2010 & Excluded (277-bp) \\
\hline 31 & L. umbrifera & HМ775852.1 & deWaard et al., 2010 & \\
\hline 32 & L. umbrosa & HM775854.1 & deWaard et al., 2010 & \\
\hline 33 & L. vacillans & HM893579.1 & deWaard et al., 2010 & \\
\hline 34 & L. atemeles & DQ116184.1 & Armstrong \& Ball, 2005 & \\
\hline 35 & L. bantaizana & DQ116178.1 & Armstrong \& Ball, 2005 & \\
\hline 36 & L. lunata & DQ149572.1 & Armstrong \& Ball, 2005 & \\
\hline 37 & L. xylina & DQ116158.1 & Armstrong \& Ball, 2005 & \\
\hline
\end{tabular}


Table 3. Proportion of each nucleotide and the bias in CO I gene.

\begin{tabular}{clccc}
\hline & $1^{\text {st }}$ codon & $2^{\text {nd }}$ codon & $3^{\text {rd }}$ codon & Mean \\
\hline A & 0.3244 & 0.14018 & 0.45085 & 0.30516 \\
$\mathrm{C}$ & 0.16304 & 0.25698 & 0.10667 & 0.17556 \\
$\mathrm{G}$ & 0.23951 & 0.16104 & 0.02060 & 0.14038 \\
$\mathrm{~T}$ & 0.27300 & 0.44179 & 0.42189 & 0.37889 \\
$\mathrm{~A}+\mathrm{T}$ bias & & & & 0.3333 \\
\hline
\end{tabular}

Chi-square test $\left(X^{2}=62.865, \mathrm{df}=135, \mathrm{P}=0.999\right)$

2010).

The PCR products were purified using Qiaquick PCR purification Kit (Qiagen. USA). Sequencing was performed using ABI PRISM Dye Terminator Cycle Sequencing Ready reaction kit (Perkin-Elmer) on ABI PRISM model 310 Genetic analyzer (PE Applied Biosystems). The sequence was alignment using BioEdit sequence alignment Editor (Hall, 1999).

\section{Base composition analysis}

We used the base frequency's option in PAUP* version 4.0b. 10 for 32-bit Microsoft Windows to evaluate the base composition of each sequence and the homogenity of the base frequency across taxa (Swofford, 2001). For the sequence divergence we chose K2P distance model.

\section{Phylogeny reconstruction}

Phylogeny reconstructions were performed with MEGA version 5.10 for Neighbor Joining (NJ) and Maximum Likelihood (ML) tree building methods (Tamura et al., 2011). The statistical confidence of a particular clade in all the tree building methods was evaluated by using bootstrap test with 1000 replications

For outgroup comparison, Orgya australis postica (No. Accession genbank: DQ116189.1) and Orgya antiqua (No. GU091292.1) from the tribe Orgyiini were used. All species of the genus Lymantria that were included in the analysis were presented in Tables $1 \& 2$.

\section{Results}

\section{Base composition}

Sequences of 42 species of Lymantria and two species outgroups, Orgya australis postica and $O$. antiqua, were alignment with no evidence of insertion and deletion. The conserved regions were found at position: 181 GATAT AGC 188; 100 ATTATAAT 107; 64 CAAATTTA 71; 199 ATAAATAA 206; 265 GAAAATGG 272; 385 TT AGGAGC 392. Aligned sequences have been submitted to the genbank with accession numbers presented in the Tables $1 \& 2$.

Table 3 shows the proportion of A-C-G-T of CO I gene, and its bias $(C)$. The bias was calculated following Irwin et al. (1991) as follow: $C=(2 / 3) \sum_{i=1}^{4}\left|c_{i}-0.25\right|$, where $c_{i}$ is base frequency $i$. The results shows that the base composition was $\mathrm{A}+\mathrm{T}$ biased $(C: 0.3333)$ with the average of $\mathrm{A}+$ $\mathrm{T}$ contents was $68 \%$.

Interspecific variation in the base composition in CO I was very low for the total nucleotides. The chi-square test of homogeneity of base frequencies across taxa indicates that there was no significant difference in the frequency of bases between taxa $\left(X^{2}=62.865, d f=135\right.$, $P=0.999$ ).

\section{Sequence divergence}

The mean of pairwise sequence divergences of $\mathrm{CO}$ I gene based on K2P distance model within Group A, B, C, $\mathrm{D}, \mathrm{E}$, and $\mathrm{F}$ were $8.97 \%, 12.06 \%, 10.86,11.66 \%, 12.56 \%$ and $5.70 \%$ respectively. The closest relationships within subgenera was a pairwise between species $L$. lunata and $L$. antennata $(0.38 \%)$, while the most distant was between L. mathura and L. lepcha (19.98\%). A pairwise sequence between $L$. praetermisa, and L. inordinata; $L$. inordinata and $L$. capnodes have no value and it indicates that these tree species have the same sequence.

Fig. 1 shows the relationship between pairwise distance for Transition (Ts) and Transversion (Tv) based on K2P distance model. Ts almost linearly increased with respect to $\mathrm{Tv}$ and exceed $\mathrm{Tv}$ in all pairwise species comparisons (except on pairwise $L$. praetermisa, and L. inordinata; L. inordinata and L. capnodes) and its linear regression was $\mathrm{Y}=0.2197 \mathrm{X}+0.0392 ; \mathrm{R}^{2}=0.0727$.

Fig. 2 shows the scatter plot of K2P distance between Transition/Transversion (Ts/Tv) and all substitutions in $\mathrm{CO}$ I gene. The means of Ts/Tv ratio in CO I gene was moderate (1.226) for insect mitochondrial gene.

\section{Phylogeny}

Neighbor Joining (NJ)

To reconstruct Neighbor joining tree, we applied distances based on Kimura-two parameter (K2P) and HKY 85 models (Kimura, 1980; Hasegawa et al., 1985). There was no different in the topology, therefore only the $\mathrm{NJ}$ tree based on K2P model was presented in Fig. 4. Based on the tree it is clear that this genus fall into 6 groups but each group weakly supported by bootstrap support, they were: Group A: (L. pulvurea $+L$. monacha $)+L$. minominis $)+L$. umbrifera $)+L$. alexandrae $)+L$. concolor $)$ ); Group B: $(L$. capnodes $+L$. praetermisa $+L$. inordinata $)$ $+L$. rhabdota $)+L$. bantaizana $)+L$. temburong $)+L$. grisea $)+($ L. dissolute + L. ekeikei $)+L$. panthera $)$ ); Group C: (L. umbrosa $+L$. dispar $)+L$. obfuscata $)+L$. albescens $)$ ) $+($ L. schaeferi + L. xylina $)+L$. Singapura $))+($ brunneiplaga $1+$ brunneiplaga 2$)+($ L. lunata $+L$. antennata $)+L$. plumbalis $)+L$. lepcha $)+($ L. narindra + L. lucescen $))$; Group 


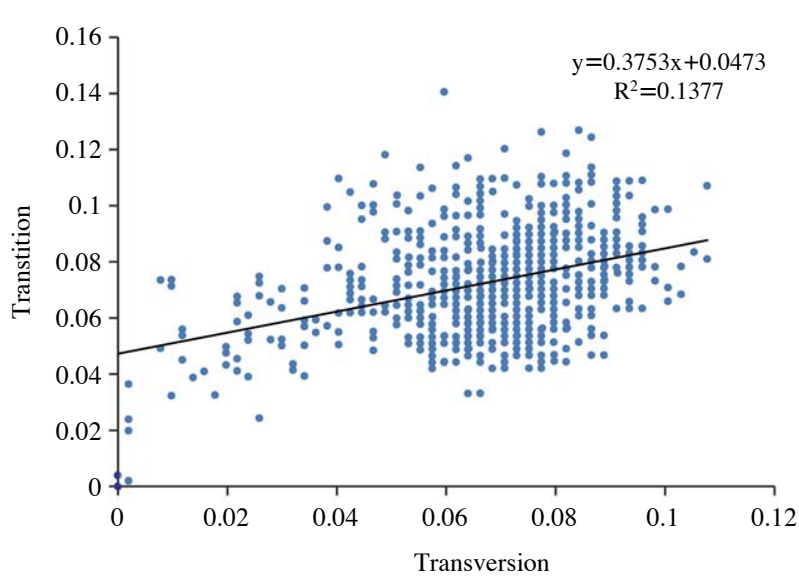

Fig. 1. Scatter plots of K2P model distances for transition (Ts) versus Transversion (Tv).

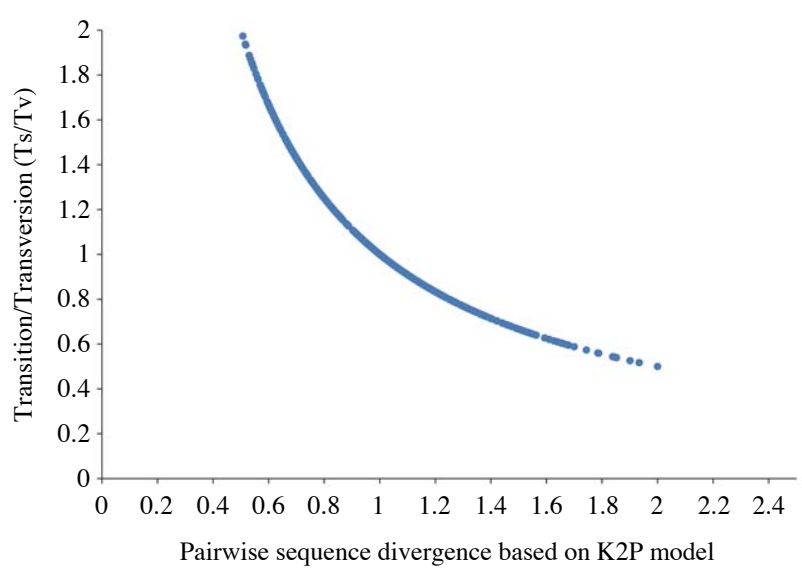

Fig. 2. Pairwise sequences divergence based on $\mathrm{K} 2 \mathrm{P}$ model versus Transition/Transversion (Ts/Tv).

D: $($ L. vacilans + L. nephrographa $)+(L$. nebulosa $+L$. sinica); Group E: (L. flavida+L. mathura) + L. nrmathura) + L. naesigi)); Group F: (L. atemeles + L. beatrix $)$.

Maximum-likelihood (ML)

The evolutionary history was inferred by using the Maximum Likelihood method based on the HasegawaKishino-Yano model. Initial trees for the heuristic search were obtained automatically by applying Neighbor-Join and BioNJ algorithms to a matrix of pairwise distances estimated using the Maximum Composite Likelihood (MCL) approach, and then selecting the topology with superior log likelihood value. A discrete Gamma distribution was used to model evolutionary rate differences among sites $(5$ categories $(+G$, parameter $=0.2107))$. The tree (Fig. 4) with the highest log likelihood $(-5641.8278)$ was almost the same as the ML from the previous study (de Waard et al., 2010). However, the relationships among these groups were not consistent with those within $\mathrm{NJ}$ tree building method, especially the position of the group D.

\section{Discussion}

The result of our study showed that CO I genes from 42 species of Lymantria was a high $\mathrm{A}+\mathrm{T}$ biased. It is consistent with mitochondrial genomes of other Lepidoptera previously reported by many authors (Reviewed in Simon et al., 1994). In other genera of Lepidoptera, high $\mathrm{A}+\mathrm{T}$ contents have been found in CO I of Helicoverpa; Glyphodes, Mythimna, Aganiinae (Kranthi et al., 2006; Sutrisno et al., 2006; Sutrisno, 2011; 2012b) which ranged from $62 \%$ to $74 \%$. The average of $\mathrm{A}+\mathrm{T}$ proportion in the present study (68\%) was comparable with those found in other genera of Lepidoptera. In addition, the bias in base compositions was found to be the greatest at the third-base position. This perhaps because first- and second-codon position were more constrained by the amino acid composition of the encoded protein (van Dorp, 2004; Zhang et al., 2011).

The sequence divergence of CO I gene within group was relatively high $(5.70 \%-12.56 \%)$. It indicates that each subgenera within genus Lymantria consists of a large number species and very diverse, especially within Group E. These values were higher with those found within group of Glyphodes (5.92-7.55\%) and subgenera within Mythimna (5.32-8.82\%) (Sutrisno et al., 2006; Sutrisno, 2012b).

The present study revealed that the transition/transversion ratio of $C O I$ within Lymantria was moderate (1.226). It indicates that Transitions (Ts) occur more frequently than Transversions (Tv), and Ts values are usually expected to exceed Tv values; however, it has been reported for some mitochondrial DNA that Tv values exceed Ts values (van Dorp, 2004; Roe \& Sperling, 2007). This is primarily because transversions erase the record of transitions after genes are saturated with the latter. In contrast, the $\mathrm{COI}$ in this study indicated that this gene was not yet saturated with transitions (Fig. 3). This finding also supports the general view that observed transition exceed transversion only when recently diverged species or slowly evolving gene are compared (van Dorp, 2004; Sutrisno et al., 2006).

The topology resulted in ML tree building method in this study was almost similar with those found in the previous study (deWaard et al., 2005) except of the position L. semperi, the group D and the group F. In the previous study $L$. simperi branch off first while in this study the group F was branch off first. It is sensible since the $L$. simperi was omitted in this study due to its sequence to short. Involving the short sequence might be misleading to the hypothetical conclusion. The previous study also showed the second same phenomenon, the position of group D was as the sister group of B while in this study 


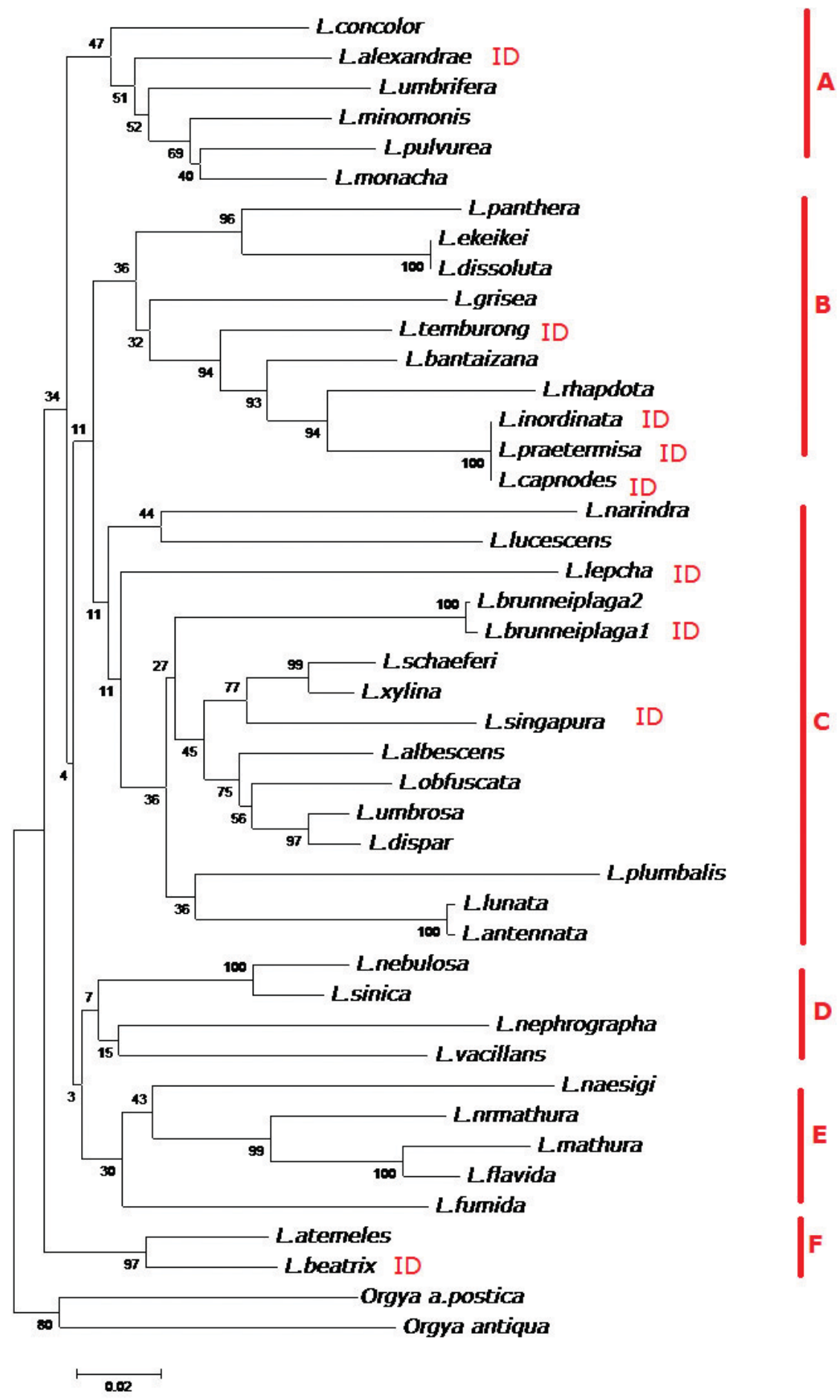

Fig. 3. Neighbor-Joining tree based on K2P distance model of all substitutions of CO I gene (Bootstrap support are shown at the nodes; $\mathrm{ID}=$ specimens from Indonesia).

that group was as sister group of A. This is because the two species with too short sequence (L. singapura and L. todara) were included in the previous study. When $L$. singapura was replaced by L. singapura from Indonesia (516-bp), this species falls into group C. Indeed, involv- ing short sequence or unequal length can cause misleading hypothetical conclusion.

Some of these findings were almost agreed with the classification based on morphological characters that was conducted by Schintlmeister (2004). He divided 


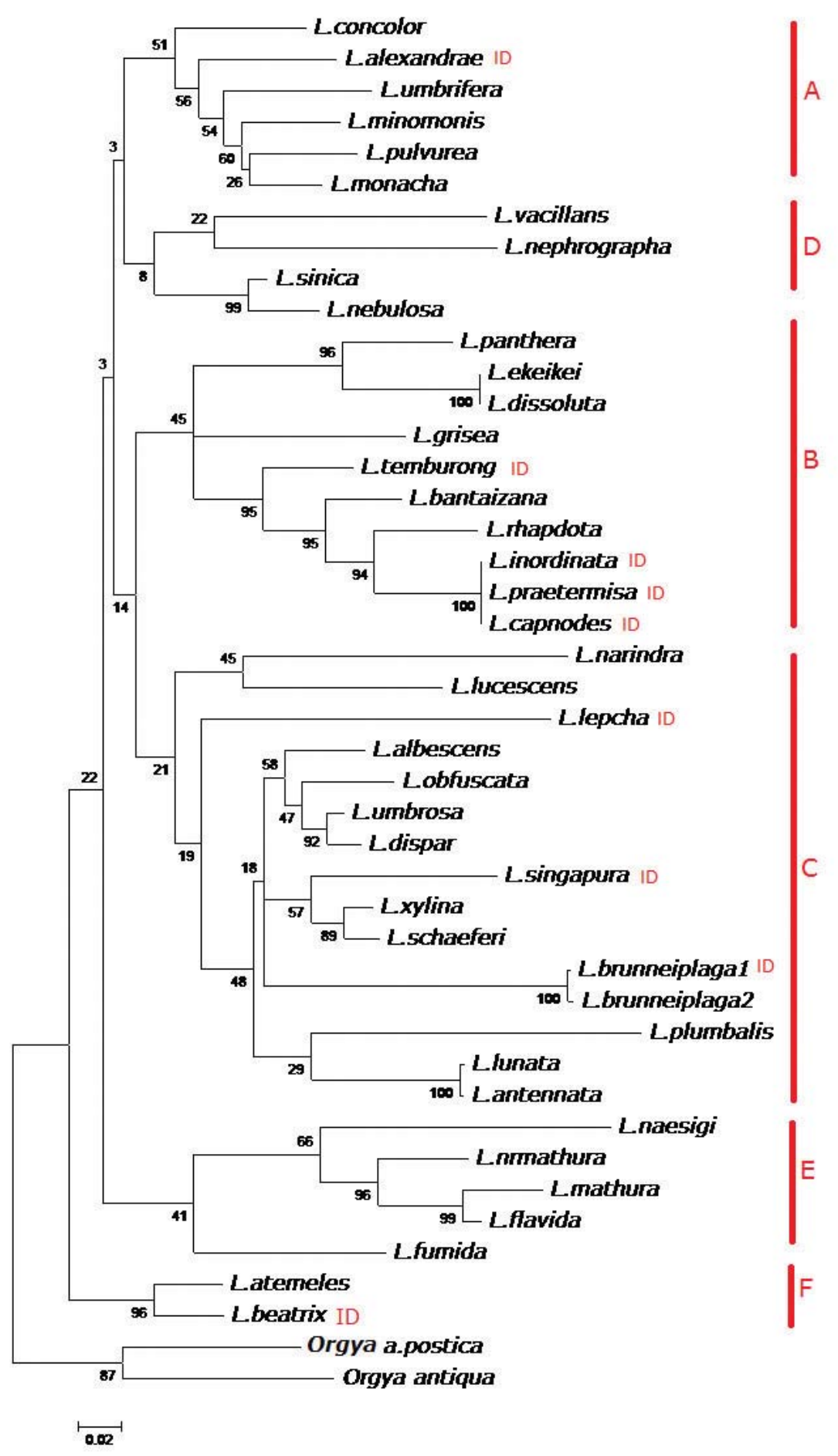

Fig. 4. Maximum likelihood tree for 43 species of Lymantria based all substitutions of CO I gene (Bootstrap support are shown at the nodes; ID=specimens from Indonesia).

Lymantria into 12 subgenera even though this subgeneric division was admitted for pragmatic reason rather than impelled by important taxonomic differences. At least there were five subgenera of them could be recovered in this analysis. Based on his classification, Group A and
D could be classified as the member of the sub genus Lymantria (Lymantria) except the position of L. nephrographa that was not included into this sub genus but it was treated as a species incertae sedis within Lymantria. The sub genus L. (Lymantria) was possibly defined by a 
basal process at the base of valve in various shaped and appressed to the inner surface of the valvae. Moreover, almost all the member of the group $\mathrm{C}$ could be classified into subgenus L. (Porthetria) except for the three species at the basal node (L. narindra, L. lucescen and L. lepcha). The subgenus L. (Porthetria) was defined possibly based on characteristic of the valve of male genitalia: an elongate arm that is either an extension of the costa or can extend from the middle of valve. In addition, the most consistent is the group $\mathrm{F}$ which could be classified into subgenus L. (Beatria) as well as group E which could be classified under subgenus L. (Nyctaria). Subgenus $L$. (Beatria) was defined by a single good apomorphy: a triangular valve with a curved, elongate dorsal projection, while L. (Nyctaria) was by a lateral digitate process arising from the ventral margin of tegumen and the deeply divided valves. On the other hand, members of sub genus L. (Collentria): L. fumida and L. grisea were splited into different groups in this analysis.

The nine Indonesian species were evolved independently and distributed into four subgenera: L. (Lymantria), $L$. (Porthetria), L. (Beatria) and Lyamntria (Spinotria). Those species are only a small part of the large genus of Lymantria that have been distributed world-widely for a long time.

The results also showed that the position of L. praetermisa, L. inordinata and L. capnodes form a single clade with strong bootstrap value (100\%). It indicates that those species have the same sequence and they are closelyrelated species. Indeed, the similarity of sequence (516bp) among them was $100 \%$. However, when the longer sequence of CO I (610-bp) was aligned, the similarity between L. capnodes and L. praetermisa or L. capnodes and $L$. inordinata was $>98 \%$. The differences was occur at the position of 100-bp first. Due to practical reason, this 100-bp first was omitted from the analysis since only 516-bp of 42 sequences that was homolog. On the other hand, L. capnodes and L. praetermissa consistently showed that they are identical species. It could be there was misidentification and further re-examination needs to be conducted. Indeed, CO I gene are very useful to characterize lymantrid species, especially to distinguish among Indonesian species.

There are many possible reasons for way that this COI gene resulted in inconsistency tree topologies in different tree building methods and given low support bootstrap for their relationships. Only very clean data will result in a similar topology tree with consistent strong bootstrap supports in different tree building methods. This study showed that CO I gene alone was not enough to produce synapomorphies on each node but this gene was able to show a good support for a certain closely-related species. Previous study showed the mitochondrial gene $C O I$ was very useful when combined with Cytochrome $b$ to resolve the relationships in the genus Morpho (Nymphalidae) (Cassildé et al., 2012), or when combined with CO II in the genus Papilio (Caterino and Sperling, 1999). In addition, the combination of the $C O I$ and $E F-1 \alpha$ increased resolution and supports most of the phylogenetic relationships suggested by separate analysis of Ectoedemia s. str. (Lepidoptera: Nepticulidae) (van Nieukerken et al., 2012).

The low bootstrap test on each node in any tree building methods was also possibly caused by many conflicts among the sequence in CO I due to the lack of species sampling in the analysis. We believed that Lymnatria included in this analysis is only a small part of the whole Lymantria in the world or about $25 \%$. These problems can be resolved only by increasing the number of sample species in the analysis to reduce the distance sequences and also by involving gene having slow evolutionary rate (Nei and Kumar, 2000; Zang, 2008). The closely-related distances among sequences will produce a robust phylogenetic relationship as indicated in the closely-related subgenus Lymantria (Beatria) or group $\mathrm{F}(L$. beatrix $+L$. atemeles) which always has a consistent strong bootstrap support in any tree building methods.

In general, all the findings in the present study suggest that monophyly of Lymantria was not supported by bootstrap support but at least there was a single aphomorphy character to support this genus. Phylogenetic analysis of 42 species of Lymantria based on mitochondrial $C O I$ gene recovered 5 of 12 subgenera. Moreover, the Indonesian Lymantria species distributed into several subgenera: Lymantria (Beatria); Lymantria (Lymantria); Lymantria (Porthetria), and Lyamntria (Spinotria). However, all internal nodes gained least supports except for the monophyly of subgenus Lymantria (Beatria). It indicates that the relationships among internal nodes proposed here were least valid due to the number of species included in the analysis which may not be enough to represent the real number of species in the nature. Further studies are needed to be done by including more other species and other more conserved genes in order to test the validity of the relationships proposed here.

\section{ACKNOWLedgements}

My greatest gratitude goes to the Head of the Research Center for Biology, for his support to this study. Many thanks are also addressed to Darmawan, Sarino, E. Cholik, and Indah for their assistance in preparing materials for the study. This study was partly supported by DNA Barcoding and study Biosystematics DIPA Project 2013, Research Center For Biology-LIPI, without which these grants it is almost impossible to conduct this research successfully. 


\section{REFERENCES}

Armstrong, K.F. and S.L. Ball. 2005. DNA barcodes for biosecurity: invasive species identification. Philosophical Transactions of the Royal Society. B: Biological Science 360(1462):1813-1823.

Ball, S.L. and K.F. Armstrong. 2006. DNA barcode for insect pest identification: a test case with tussock moths (Lepidoptera: Lymantriidae). Canadian Journal Forest Research 36:337-350.

Cassildé, C., P. Blandin and J.F. Silvain. 2012. Phylogeny of the genus Morpho Fabricius 1807: insights from two mitochondrial genes (Lepidoptera: Nymphalidae). Annales de la Société entomologique de France (N.S.): International Journal of Entomology 48(1-2):173-188. doi: 10.1080/ 00379271.2012 .10697762 .

Caterino, M.S. and F.A. Sperling. 1999. Phylogeny Papilio based on mitochondrial cytochrome oxidase I and II genes. Molecular Phylogenetics Evolution 11(1):122-137.

Collenette, C.L. 1948. The Lymnatriidae of Java. Annal Magazine of Natiural History 12:685-744. http://dx.doi. org/10.1080/00222934808653942.

deWaard, J.R., A. Mitchell, M.A. Keena, D. Gopurenko, L.M. Boykin, K.F. Armstrong, M.G. Pogue, J. Lima, R. Floyd, R.H. Hanner and L.M. Humble. 2010. Towards a global barcode library for Lymantria (Lepidoptera: Lymantriinae) Tussock moths of biosecurity concern (Citations: 1). Journal: PLOS One 5(12):1-10.

Hall, T.A. 1999. BioEdit: a user-friendly biological sequence alignment editor and analysis program for window 95/98/ TNT. Nucleic Acid Symposium Seri 41:95-98.

Hasegawa, M., H. Kishino and T. Yano. 1985. Dating the human-ape splitting by a molecular clock of mitochondrial DNA. Journal Molecular and Evolutionary 22:160-174.

Hebert, P.D., J.R. deWaard and J.F. Landry. 2010. DNA barcodes for $1 / 1000$ of the animal kingdom. Biology Letters 6(3):359-362.

Holloway, J.D. 1999. The moth of Borneo Part 5 Lymantriidae. The Malayan Nature Journal 53:1-188.

Irwin, D.M., T.D. Kocher and A.C. Wilson. 1991. Evolution of the cytochrome $b$ gene of mammals. Journal of Molecular Evolutionary 32:128-144.

Kim, M.I., X. Wan, M.J. Kim, H.C. Jeong, N.H. Ahn, K.B. Kim, Y.S. Han and I. Kim. 2010. Phylogenetic relationships of True butterflies (Lepidoptera: Papilionoidea) inferred from COI, 16S rRNA and EF-1 $\alpha$ sequences. Mollecules and Celles 30:409-425.

Kimura, M. 1980. A simple method for estimating evolutionary rate of base substitution through comparative studies of nucleotide sequences. Journal of Molecular Evolutionary $16: 111-120$.

Kranthi, S., K.R. Kranthi, A.A. Bharose, S.N. Syed, C.S. Dhawad, R.M. Wadaskar and E.K. Patil. 2006. Cyto- chrome oxidase I sequence of Helicoverpa (Noctuidae: Lepidoptera) species in India-Its utility as a molecular tool. Indian Journal of Biotechnology 5:195-199.

Matsuki, M., M. Kay, J. Serin, R. Floyd and J.K. Scott. 2001. Potential risk of accidental introduction of Asian Gypsy moth (Lymantria dsipar) to Australia: effect of climatic conditions and suitability of native plants. Agriculture Forest Entomology 3:305-320.

Nei, M. and S. Kumar. 2000. Molecular evolution and phylogenetics. Oxford University Press, London.

Roe, A.D. and F.A.H. Sperling. 2007. Patterns of evolution of mitochondrial cytochrome c oxidase I and II DNA and implications for DNA barcoding. Molecular Phylogenetics and Evolution 44:325-345. doi: 10.1016/j.ympev.2006. 12.005 .

Schintlmeister, A. 2004. The taxonomy of the genus Lymantria Hubner [1819] (Lepidoptera: Lymantriidae). Quadrifina $7: 1-248$.

Simon, C., F. Frati, A. Beckenbach, B. Crespi, H. Liu and P. Flook. 1994. Evolution, Weighting, and Phylogenetic utility of Mitochondrial Gene Sequences and a Compilation of conserved Polymerase Chain Reaction Primers. Annals Entomological Society 87(6):651-701.

Sutrisno, H., H. Suputa, S. Purnomo, C. Polandono, R. Waluyo, Ubaidillah, Darmawan, Ismail, I. Hidayat and N. Widyastuti. 2013. Notes on some biological aspects of Arctornis riguata Snellen (Lepidoptera: Lymantriidae). HAYATI (Journal of Biosciences) 19(4):47-50.

Sutrisno, H., N. Azuma and S. Higashi. 2006. Molecular phylogeny of the Indo-Australia Glyphodes and allied genera (Insecta: Lepidoptera: Crambidae) inferred from CO I, CO II and EF-1 alpha genes. Journal of Species Diversity 11:57-69.

Sutrisno, H. 2008. Species Status of yelow stem borer Scirpophaga incertulas (Lepidoptera: Pyralidae) based on CO I gene sequences. Treubia 36:37-47.

Sutrisno, H. 2011. Molecular Phylogeny of Indonesian Aganaine Moths (Lepidoptera: Noctuidae) based on CO I gene. Treubia 38:71-186.

Sutrisno, H. 2012a. The impact of storage time of museum insect specimen on PCR success: case study on moth collection in Indonesia. HAYATI (Journal of Biosciences) 19(2):99-104.

Sutrisno, H. 2012b. Molecular phyilogeny of Indonesian armyworm Mythimna (Lepidoptera: Noctuidae). HAYATI (Journal of Biosciences) 19(2):60-65.

Swofford, D.L. 2001. PAUP*. Phylogenetic analysis using parsimony (* and Other Methods). Version $4.0 \mathrm{~b} 10$ for 32-bit Microsoft Windows. Sinauer Associates, Sunderland, Massachusetts.

Tamura, K., D. Peterson, N. Peterson, G. Stecher, M. Nei and S. Kumar. 2011. MEGA5: Molecular evolutionary genetics analysis using maximum likelihood, evolutionary distance, and maximum parsimony Methods. Molecular 
Biology and Evolution 28:2731-2739.

Tsao, W.C. and W.B. Yeh. 2008. DNA-Based Discrimination of Subspecies of Swallowtail Butterflies (Lepidoptera: Papilioninae) from Taiwan. Zoological Studies 47(5): 633-643.

van Dorp, K. 2004. Molecular systematics of Lycaena F., 1807 (Lepidoptera: Lycaenidae) - Some preliminary results. Procceding Netherland Entomological society 15:65-70. van Nieukerken, E.J., C. Doorenweerd, F.R. Stokvis and D.S.J. Groenenberg. 2012. DNA barcoding of the leaf-mining moth subgenus Ectoedemia s. str. (Lepidoptera: Nepticulidae) with COI and EF1- $\alpha$ : two are better than one in recognising cryptic species. Contributions to Zoology 81(1):124.
Yamamoto, S. and T. Sota. 2007. Phylogeny of the Geometridae and the evolution of winter moths inferred from a simultaneous analysis of mitochondrial and nuclear genes. Molecular Phylogenetics and Evolution 44:711-723. doi: 10.1016/j.ympev.2006.12.027.

Yang, Z. 2008. Computational Molecular Evolution. Oxford University Press, London.

Zhang, M., T.W. Cao, Y. Zhong, Y.P. Guo and E.B. Ma. 2011. Phylogeny of Limenitidinae Butterflies (Lepidoptera: Nymphalidae) Inferred from Mitochondrial Cytochrome Oxidase I Gene Sequences. Agricultural Sciences in China 10(4):566-575.

Submitted: September 16, 2013, Accepted: February 10, 2014 